\title{
Superconducting conference yields new temperature record
}

\section{Interlaken, Switzerland}

THE record for high-temperature superconductivity has been broken yet again. On Wednesday night last week, Dr Paul Grant of the IBM research laboratory in Almaden, California announced the attainment of zero resistance at $125 \mathrm{~K}$ in a thallium-barium-calcium-copper oxide. At the time of the announcement, this represented an increase of over 20 degrees on the highest published zero-resistance temperature.

Grant was speaking at an evening session of the week-long International Conference on High-Temperature Superconductivity and Materials and Mechanisms of Superconductivity, which brought 1,200 people from 36 countries to Interlaken, mostly to hear reports of the latest research on the high-temperature oxide superconductors. Of the 800 talks and posters, more than 750 reported work on the oxide materials

Most of the excitement was generated by reports on the new rare-earth-free bismuth and thallium superconductors. Superconductivity at over $100 \mathrm{~K}$ in bismuth-strontium-calcium-copper oxide had been reported by Hiroshi Maeda less than six weeks before the conference began (see Nature 331, 377; 1988), yet more than 30 speakers were able to report results on this system. Only a few had had time to work on the thallium system, discovered by Z.Z. Sheng and A.M. Hermann of the University of Arkansas only in mid-

\section{Thin film already}

\section{Tokyo}

AlthOUGH bismuth-strontium-calciumcopper oxide (see Nature, 331, 377; 1988) superconductors were discovered barely a month ago, a Japanese company has already succeeded in making a thin film of the new material. The same development took many months for the rare-earth superconductors.

Matsushita Electric Industrial Co. announced last week that it has made a polycrystalline thin film that superconducts at $100 \mathrm{~K}$, at least ten degrees higher than reported for films of yttrium-based copper oxides. Although the increase in critical temperature is modest, it does double the operating margin above $77 \mathrm{~K}$, the temperature of liquid nitrogen.

The film has a critical current density of $10^{5} \mathrm{~A} \mathrm{~cm}^{-2}$, about half that reported for polycrystalline rare-earth thin films, but Matsushita researchers are confident that they can increase current-carrying capacity by preparing monocrystalline thin films.
February (their report of the discovery is published on p.138 of this issue), but by the end of the week $Z$. Zhao of the Institute of Physics in Beijing was able to announce that his group had measured zero resistance at $120 \mathrm{~K}$, almost equalling Grant's record. The frenetic pace at which work is proceeding around the world was evident as speakers presented data that were only hours old, hot off the facsimile machine.

Although the race to ever-higher transition temperatures lent spice to the atmosphere, it did not overshadow the equally important scientific advances reported on the new materials. It was generally agreed that there are two closely related superconductors in the bismuth family, with stoichiometry near $\mathrm{Bi}_{2}(\mathrm{Sr}$, Ca) ${ }_{3} \mathrm{Cu}_{2} \mathrm{O}_{8}$ and nominal transition temperatures of about 80 and $105 \mathrm{~K}$. Several groups have determined the crystal structure of the lower-temperature phase and find that it resembles the $40-\mathrm{K}$ lanthanum and $90-\mathrm{K}$ yttrium superconductors in containing perovskite-like layers with extended planes of copper and oxygen. But the linear copper-oxygen 'chains' thought by some to play a role in the elevated transition temperature of the yttrium compound are absent in the bismuth structure, which instead has double layers of bismuth oxide.

The absence of chains came as an optimistic sign to many who, a year after Paul Chu's discovery of the yttrium superconductor, had begun to wonder whether there were any more high-temperature superconductors to be discovered. As R.J. Cava, of AT\&T Bell Laboratories, said at the conference, "The yttrium structure, with its copper-oxide chains, was very special - almost a one-off. But just about every compound with copper and oxygen has planes." The discovery of the thallium superconductors, which appear to be structurally similar to the bismuth compounds, reinforces the view that the field is now wide open for further discoveries. In fact, as thallium is highly toxic and bismuth is in short supply, both materials may be of greater scientific than technological importance.

Although the new materials stole the limelight, the conference was also notable for the large volume of high-quality work reported on the now suddenly 'old' lanthanum and yttrium materials. Steady progress was evident on the materials side, as critical currents in both thin-film and bulk material continue to increase. But attempts to understand the mechanism of the superconductivity are still frustrated by the prevalence of conflicting experimental results, largely owing to

\section{Indian science budget} New Delhi

INDIA's annual budget for 1988-89 provides Rs17,000 million ( $£ 850$ million) for scientific research and development. This is 6 per cent of the total and 20 per cent more than the scientific agencies spent last year. In comparison, defence gets a whopping $£ 6,500$ million, of which $£ 320$ million is for military research (see table).

As in the past, the Departments of Atomic Energy and Space between them share 70 per cent of the budget. The Department of Atomic Energy is setting up a major research centre for accelerators and lasers at Indore in Madhya Pradesh, and the Space Department plans to build a multi-million dollar facility for developing cryogenic engines for its planned geostationary launch vehicle.

Spending on biotechnology and microelectronics is to increase and $£ 4$ million has been ear-marked for work on hightemperature superconductors. Prime Minister Rajiv Gandhi is himself chairman of the Apex committee that is directing superconductor research. New facilities for which provisions have been made include a medium-range weather forecasting network using the supercomputer being imported from the United States, a pilot plant for manufacturing amorphous silicon for solar cells and a second permanent station in Antarctica.

Gandhi's budget in a drought year is predictably biased in favour of farmers and the rural poor. By exempting taxes on electronic items made in villages, he hopes to push industries to rural areas and create jobs. K. S. Jayaraman

Atomic energy Rs (millions)

Space 8,490 Electronics

Ocean development 960

Biotechnology

Industrial research

1,400

Medical research

220
450

Other

880

Defence research

930

6,400

variable sample quality.

Two years ago, the first conference on Materials and Mechanisms of Superconductivity in Ames, Iowa was attended by about 250 people; the record superconducting transition temperature then stood at $23 \mathrm{~K}$. At Interlaken the corresponding figures were over 1,200 people and $125 \mathrm{~K}$, leading T.H. Geballe of Stanford University to suggest that conference attendance grew in proportion to transition temperature. As Geballe has been charged with responsibility for the next conference in the series, to take place in the summer of 1989 in the San Francisco area, he has mixed feelings about the prospect of room-temperature superconductivity. 